\title{
ABERTURA DE CREDITOS ADICIONAIS: ESTUDO SOB A ÓTICA DA TEORIA DA ESCOLHA PÚBLICA
}

\author{
OPENING OF ADDITIONAL CREDITS: STUDY FROM \\ THE OPTICAL OF PUBLIC CHOICE THEORY
}

Francisco de Assis Carlos Filho - francisco.assis.filho@gmail.com ${ }^{1}$

Possui graduação em Ciências Contábeis (2005). Especialização em Contabilidade e Auditoria Pública (2006). Doutor em Controladoria e Administração (UFC), Mestre em Ciências Contábeis (UFPE). Professor Adjunto da Universidade de Pernambuco (UPE). Orcid: https://orcid. org/oooo-0002-9312-2896
RESUMO: No intuito de testar a teoria da escolha pública, o objetivo geral da presente pesquisa foi relacionar se o vínculo partidário dos prefeitos dos municípios paraibanos com a manipulação do orçamento no setor público, através da anulação de créditos adicionais. A amostra foi constituída por todos 223 municipios do estado da Paraíba. Os anos analisados foram 2017 e 2018. Os principais resultados foram de que houve aumento significativo nos orçamentos das prefeituras paraibanas de 2017 para 2018. Por outro lado, em média 25,9\% em 2017 e 22,5\% em 2018 do que foi planejado foi anulado. O teste de wilcoxon demonstrou que essa diminuição de anulação nos orçamentos das prefeituras de 2017 para 2018 foi estatisticamente significativa. O teste de Kruskal-Wallis indicou que não houve diferença estatística significativa entre os partidos políticos em relação as anulações do orçamento nem em 2017 e nem em 2018. Dessa forma não foi aceita a hipótese proposta nessa pesquisa, em que o vinculo partidário dos prefeitos dos municípios paraibanos difere em relação a manipulação do orçamento no setor público. Esse resultado encontra amparo nos pressupostos da teoria da escolha pública. Variáveis como ano e mandato eleitoral seriam interessantes de serem estudadas no contexto dessa pesquisa.

palavras chave: Teoria da escolha pública. Orçamento Público. Créditos adicionais.

ABSTRACT: In order to test the theory of public choice, the general objective of the present research was to relate whether the party bond of the mayors of the municipalities of Paraíba with the manipulation of the budget in the public sector, through the cancellation of additional credits. The sample consisted of all 223 municipalities in the state of Paraíba. The years analyzed were 2017 and 2018. The main results were that there was a significant increase in the budgets of Paraíba city halls from 2017 to 2018. On the other hand, on average $25.9 \%$ in 2017 and $22.5 \%$ in 2018 of what was planned was canceled. The Wilcoxon test demonstrated that this decrease in the cancellation of the budgets of city halls from 2017 to 2018 was statistically significant. The Kruskal-Wallis test indicated that there was no statistically significant difference between political parties in relation to budget cancellations, neither in 2017 nor in 2018. Thus, the hypothesis proposed in this research, in which the party link between the mayors of the Paraíba municipalities differ in relation to budget manipulation in the public sector. This result finds support in the assumptions of the theory of public choice. Variables such as year and electoral mandate would be interesting to be studied in the context of this research. KEYwORDs: Public choice theory. Public Budget. Additional credits. 
Data de Submissão: 17/11/2020

Data de Revisão: 14/01/2021

Data de Aceitação: 15/01/2021 


\section{INTRODUÇÃO}

Nos dias de hoje no Brasil existe grande interesse em examinar se existem diferenças ideológicas dos partidos políticos e se essas diferenças são demonstradas efetivamente na conduta dos políticos relacionados.

Segundo a Public Choice Teory, no Brasil conhecida como Teoria das Escolhas Públicas (TEP), empregada como teoria de base deste estudo, os agentes públicos tomam decisões levando em consideração interesses próprios ou de seu grupo. Segundo (Udehn, 1995) são três os pressupostos da TEC: o pressuposto de auto-interesse, a concepção de interações sociais como trocas de mercado e o individualismo metodológico. Logo, sob a ótica da TEC, partidos de esquerda, direita e centro (esquerda e direita) possuem comportamentos iguais no intuito de maximizarem a sua utilidade.

Estudo de (Grateron, 1999) afirma que à falta de controle adequado sobre uma determinada gestão, implica um conjunto de atos que resultam no uso indevido dos recursos pertencentes ao Estado em benefício próprio ou de terceiros.

No Brasil existem 35 partidos políticos e é consagrado na literatura que não existem tantas ideologias políticas diferentes. Desta forma, as ideologias dos partidos políticos não explicam o comportamento e a forma de como são planejadas as políticas públicas ou de como são elaborados os orçamentos públicos.

De acordo com (Procopiuck, Machado, Resende, \& Bessa, 2007) o orçamento é visto como uma peça legal pela qual, para cada exercício financeiro, são identificadas as fontes de recursos e indicados os seus destinos, de acordo com programas de antemão elaborados.

Corroborando (Almeida \& Costa, 2019, p. 560) afirmam que o orçamento "é de total relevância para a administração pública, pelo fato de ser um instrumento governamental que planeja as atividades do Setor Público e organiza de forma adequada e com clareza os recursos de uma sociedade".

Em meio as diversas possibilidades de estudos sobre orçamento público, este estudo irá tratar os denominados créditos adicionais. (Rocha, 2009) explica que estudo sobre créditos adicionais são importantes para constatar a sustentação do planejamento do governo ou para explicar por qual razão o planejamento foi alterado.

Cabe a menção de que os créditos adicionais são regulamentados pela Lei 4.320 (1964) que classifica três tipos de créditos adicionais: suplementares, especiais e extraordinários. Os suplementares e extraordinários não dependem de autorização do poder legislativo, apenas os créditos adicionais especiais dependem.

No entendimento de (C. F. da Cruz \& Afonso, 2018) um ponto crítico é que muitos agentes envolvidos têm incentivos para expandir o orçamento e criar défcit, enquanto outros têm incentivos para internalizar as restrições do orçamento público. Esse entendimento justifica o 
estudo do planejamento no setor público na perspectiva das previsões orçamentárias.

A respeito disso, estudo de (Kanayama, Tomio, \& Robl Filho, 2017) esclarece que os últimos Presidentes da República utilizaram os créditos adicionais suplementares e extraordinários como instrumentos de ampliação do poder orçamentário. Dificuldades econômicas e expansão do poder decisório do Presidente da República fizeram com que algumas situações, as quais deveriam ser excepcionais, tornaram-se regulares. Ainda segundo os autores, os créditos adicionais não deverão ser utilizados para desequilibrar o orçamento ou para criar orçamento paralelo. Muito menos para fortalecer artificialmente o caixa estatal em épocas de crise.

Em uma esfera menor mas não menos importante encontram-se os municípios. Segundo (Varela, Martins \& Corrar, 2009) a administração pública brasileira tem vivido um intenso processo de transformação em que a descentralização tem sido uma estratégia comum que favorece a transferência de poder, recursos e atribuições para os governos locais. Assim, de acordo com os autores, o município é o ente federativo que mais tem sofrido os impactos desse processo de mudança da administração pública brasileira, por estar sendo considerado depositário das reais possibilidades de intervenção do Estado e, ao mesmo tempo, por estar despreparado para assumir as novas responsabilidades a ele direcionadas.

Diante do exposto, no intuito de testar a teoria das escolhas públicas no âmbito do planejamento municipal, o objetivo da presente pesquisa é relacionar o vínculo partidário dos prefeitos dos municípios paraibanos com a manipulação do orçamento no setor público, através da anulação de créditos adicionais.

Trata-se de uma pesquisa descritiva com abordagem quantitativa. Os valores planejados/orçados por cada município serão analisados e confrontados, para efeito de análise, com os valores anulados do orçamento em igual período.

Desta forma, o presente estudo está estruturado em 4 seções, a partir desta introdução, sendo o referencial teórico na seção 2, seguida da metodologia na seção 3. As análises do estudo são descritos na seção 4 e finalmente a conclusão é apresentada na seção 5, seguida das referências.

\section{REFERENCIAL TEÓRICO}

\subsection{TEORIA DA ESCOLHA PÚBLICA}

Durante a década de 50 do século passado, a Public Choice Theory ou em português: Teoria da Escolha Pública (TEP) foi desenvolvida e ganhou expressão na academia ao longo do tempo, notadamente quando o seu idealizador, o professor James M. Buchanan Jr., foi laureado com o Prêmio Nobel de Economia em 1986, em decorrência do trabalho 
seminal da TEP, "The Calculus of consent: logical foundations of constitutional democracy" (O cálculo do consenso: a fundação lógica da democracia constitucional), datado de 1962.

Segundo (Pereira, 1997) a TEP nas últimas décadas impõe-se como a principal crítica a outra teoria econômica que motiva a intervenção do Estado na economia, Welfare Economics, ou teoria do bem-estar. De um lado a teoria do bem-estar centra os seus estudos na análise dos fracassos do mercado que abonam a intervenção do Estado. Por outro lado, a TEP vem explicar e ilustrar os fracassos do governo e os seus limites de intervenção.

De acordo com (Dias, 2010) Buchanan exibe as duas grandes preocupações que podem ser identificadas de maneira subjacente quando da elaboração da TEP. A primeira é em relação à exagerada matematização, ou seja, preocupação excessiva na elaboração de modelos. Dessa forma, os economistas esqueciam-se do que era essencial: compreender as motivações que explicam as decisões dos agentes econômicos. A segunda era sobre a politização das decisões econômicas. Dessa maneira, a racionalidade econômica é superada pelos interesses políticos envolvidos na tomada de decisões.

Essas preocupações ficam evidentes quando observamos os pressupostos da TEP. Segundo (Udehn, 1995)são três os pressupostos: o pressuposto de auto-interesse; a concepção de interações sociais como trocas de mercado e o individualismo metodológico.

Estudo empírico de (Fabre, Scheeffer, Dallabona, \& Kroetz, 2018) que teve como objetivo relacionar o vínculo político-partidário dos prefeitos com a aplicação de recursos em gestão ambiental sob a ótica da TEP, concluiram que o componente ideológico garante certa previsibilidade ao comportamento dos agentes públicos.

\subsection{CRÉDITOS ADICIONAIS E HIPÓTESES DE PESOUISA}

De acordo com (Sanches, 1996) desde 09 de Setembro de 1850, através da Lei 589 , que os créditos adicionais fazem parte do orçamento público brasileiro. Hoje, os créditos adicionais são disciplinados pela Lei 4.320/64, Constituição Federal de 1988 e Lei de Responsabilidade Fiscal de 2001.

Na definição da Lei 4.320/64 (BRASIL, 1964) os créditos adicionais são: "as autorizações de despesa não computadas ou insuficientemente dotadas na Lei de Orçamento." E são classificadas em suplementares, especiais e extraordinários.

Estudo de (Rocha, 2009) esclarece de que os créditos adicionais existem para resolver basicamente dois problemas classicos dos orçamentos: a não existência de crédito orçamentário para atender alguma despesa; e a existência de crédito orçamentário insuficiente para atendimento de alguma despesa.

No Brasil os estudos sobre os créditos adicionais ainda escontra-se em estágio elementar, dada a falta de transparência dos entes públicos. Situação essa que vem se modificando. Já é possível encontrarmos 
estudos sobre créditos adicionais.

Estudo de (Baldissera, Costa, Asta, \& Fiirst, 2018) analisou a influência do ano eleitoral, da mudança de gestor público e do mandato eleitoral sobre a abertura de créditos adicionais nos municípios do Paraná. A pesquisa concluiu que as variáveis ano eleitoral, mandato eleitoral, ideologia política, coligação partidária e aspecto socioeconômico, exercem influência positiva e significativa na abertura de créditos adicionais.

Pesquisa realizada com municípios portugueses, detectaram que previsões otimistas da receita, inércia na execução da despesa, desvios nas receitas próprias e déficites orçamentários (Martins \& Correia, 2015) são as motivações que agravam os desvios orçamentários.

Diante dessas circunstâncias, sob a luz da teoria da escolha pública, as seguintes hipóteses foram formuladas:

$\mathrm{H}_{0}$ : $\mathrm{O}$ vinculo partidário dos prefeitos dos municípios paraibanos não difere em relação a manipulação do orçamento no setor público, através da anulação de créditos adicionais.

$\mathrm{H}_{1}$ : O vinculo partidário dos prefeitos dos municípios paraibanos difere em relação a manipulação do orçamento no setor público, através da anulação de créditos adicionais.

\section{METODOLOGIA}

Este estudo é classificado como descritivo, usando dados documentais, por meio de uma abordagem quantitativa para analisar a relação do vínculo partidário dos prefeitos dos municípios paraibanos com a manipulação do orçamento no setor público, através da anulação de créditos adicionais. A amostra da pesquisa consiste nos 223 municípios paraibanos. Os anos analisados foram 2017 e 2018, o que resultou no total de 446 observações.

A Tabela 1, explicita o método de coleta de dados.

Tabela 1 - Operacionalização da coleta de dados

\begin{tabular}{c|c}
\hline Descrição & Coleta \\
\hline Créditos Adicionais & $\begin{array}{c}\text { Site do Tribunal de Contas do Estado da } \\
\text { Paraíba (TCEPB). “Sagres 50.0” }\end{array}$ \\
\hline Informações eleitorais & Site do Tribunal Superior Eleitoral (TSE) \\
\hline $\begin{array}{c}\text { População de cada } \\
\text { município }\end{array}$ & $\begin{array}{c}\text { Site do Instituto Brasileiro de Geografia e } \\
\text { Estatística (IBGE) }\end{array}$ \\
\hline
\end{tabular}

FONTE: Dados da pesquisa (2019)

O software "sagres 50.0" disponibilizado pelo TCEPB, possibilitou a coleta dos créditos adicionais separados por classificação, suplementar, especial e extraordinário. Ademais, também é possível coletar os valores que foram anulados. Cabe ressaltar que essas informações não eram disponíveis para o público até o final do ano de 2018. Por "in- 
Revista de Gestão Pública

PRÁTICAS E DESAFIOS

ISSN: 2177-1243

formações eleitorais" entenda-se o partido político ao qual o gestor municipal está vinculado. Por fim, foi necessário a coleta da população para os testes com objetivos de comparação. NaTabela 2, pode-se visualisar a operacionalização desta pesquisa.

Tabela 2 - Variáveis utilizadas na pesquisa

\begin{tabular}{|c|c|c|}
\hline Variáveis & Descrição & $\begin{array}{l}\text { Análise } \\
\text { utilizada }\end{array}$ \\
\hline Orçamento & $\begin{array}{l}\text { Total do orçamento para o } \\
\text { município no ano x }\end{array}$ & $\begin{array}{l}\text { Descritiva e } \\
\text { Wilcoxon }\end{array}$ \\
\hline \multirow{3}{*}{ Créditos Adicionais } & Suplementar & \multirow{3}{*}{$\begin{array}{l}\text { Descritiva e } \\
\text { Wilcoxon }\end{array}$} \\
\hline & Especial & \\
\hline & Extraordinário & \\
\hline Anulação & $\begin{array}{l}\text { Total do montante anulado no } \\
\text { orçamento para o município no } \\
\text { ano } x\end{array}$ & $\begin{array}{l}\text { Descritiva e } \\
\text { Wilcoxon }\end{array}$ \\
\hline Anulado/Orçamento & $\begin{array}{l}\text { Quociente do que foi anulado em } \\
\text { relação ao que foi orçado }\end{array}$ & $\begin{array}{l}\text { Descritiva e } \\
\text { Wilcoxon }\end{array}$ \\
\hline $\begin{array}{l}\text { Anulado/Orçamento } \\
\text { por partido político }\end{array}$ & $\begin{array}{l}\text { Quociente do que foi anulado } \\
\text { em relação ao que foi orçado por } \\
\text { partido político }\end{array}$ & $\begin{array}{l}\text { Descritiva e } \\
\text { Kruskal-Wallis }\end{array}$ \\
\hline $\begin{array}{l}\text { Informações } \\
\text { eleitorais }\end{array}$ & $\begin{array}{l}\text { Partido político que pertence o } \\
\text { gestor/prefeito de cada município }\end{array}$ & $\begin{array}{l}\text { Descritiva e } \\
\text { Kruskal-Wallis }\end{array}$ \\
\hline $\begin{array}{c}\text { População de cada } \\
\text { município }\end{array}$ & População de cada município & Descritiva \\
\hline
\end{tabular}

FONTE: Dados da pesquisa (2019)

Em relação a analise dos dados, iniciou-se com análise descritiva no intuito de apresentar os dados da amostra do presente trabalho. Concomitantemente foi empregada a técnica estatística não-paramétrica denominada de teste de Wilcoxon com o propósito de testar duas amostras, ou seja, 2017 e 2018. Esse teste foi empregado para testar se os orçamentos, os créditos suplementares e especiais, a anulação e o que foi anulado em relação ao que foi orçado, tiveram diferença significativa nos anos analisados.

Em seguida a técnica utilizada foi o teste não-paramétrico de Kruskal-Wallis com a finalidade de testar as dezoitos amostras independentes que contem essa pesquisa (dezoito partidos políticos) em relação a variável anulado/orçado por partido político, nos anos de 2017 e 2018. 


\section{ANÁLISE DOS DADOS}

Essa seção foi dividida em duas partes, na primeira foi realizada análise descritiva com o propósito de descrever e sumarizar os dados da amostra do presente trabalho. Na segunda parte, uma serie de medições inferenciais foram testadas com o intuito de verificarmos os objetivos dessa pesquisa. 


\section{Revista de Gestão Pública}

4.1 ANÁLISE DESCRITIVA

Nesta primeira parte da análise é apresentada a participação por partido político em relação a quantidade de cidades e o tamanho da população de cada cidade.

Tabela 3 - Partidos políticos por cidades

\begin{tabular}{|c|c|c|c|c|}
\hline № & Partido & Q & $\%$ & $\begin{array}{c}\% \\
\text { Acumulado }\end{array}$ \\
\hline 1 & PSB & 54 & 24,22 & 24,22 \\
\hline 2 & PSDB & 37 & 16,59 & 40,81 \\
\hline 3 & PMDB & 31 & 13,90 & 54,71 \\
\hline 4 & PSD & 25 & 11,21 & 65,92 \\
\hline \multirow{2}{*}{5} & PTB & 17 & 7,62 & 73,54 \\
\hline & DEM & 17 & 7,62 & 81,17 \\
\hline 7 & PR & 13 & 5,83 & 87,00 \\
\hline 8 & PDT & 7 & 3,14 & 90,13 \\
\hline 9 & PP & 6 & 2,69 & 92,83 \\
\hline \multirow{3}{*}{10} & PSC & 3 & 1,35 & 94,17 \\
\hline & PT do B & 3 & 1,35 & 95,52 \\
\hline & PSL & 3 & 1,35 & 96,86 \\
\hline 13 & PRB & 2 & 0,90 & 97,76 \\
\hline \multirow{6}{*}{14} & PTN & 1 & 0,45 & 98,21 \\
\hline & PMD & 1 & 0,45 & 98,65 \\
\hline & PMN & 1 & 0,45 & 99,10 \\
\hline & PRP & 1 & 0,45 & 99,55 \\
\hline & $\mathrm{PT}$ & 1 & 0,45 & 100,00 \\
\hline & TOTAL & 223 & 100 & - \\
\hline
\end{tabular}

FONTE: Dados da Pesquisa (2019)
Tabela 4 - População por partidos políticos

\begin{tabular}{c|c|c|c|c}
\hline № & Partido & População & $\%$ & \% Acumulado \\
\hline 1 & PSDB & 1.027 .737 & 25,71 & 25,71 \\
\hline 2 & PSD & 1.025 .220 & 25,65 & 51,37 \\
\hline 3 & PSB & 757.719 & 18,96 & 70,32 \\
\hline 4 & PMDB & 297.212 & 7,44 & 77,76 \\
\hline 5 & DEM & 169.735 & 4,25 & 82,01 \\
\hline 6 & PTB & 131.550 & 3,29 & 85,30 \\
\hline 7 & PP & 131.088 & 3,28 & 88,58 \\
\hline 8 & PTN & 96.550 & 2,42 & 91,00 \\
\hline 9 & PR & 90.346 & 2,26 & 93,26 \\
\hline 10 & PRP & 66.680 & 1,67 & 94,92 \\
\hline 11 & PDT & 61.513 & 1,54 & 96,46 \\
\hline 12 & PSL & 38.739 & 0,97 & 97,43 \\
\hline 13 & PT do B & 31.507 & 0,79 & 98,22 \\
\hline 14 & PRB & 19.103 & 0,48 & 98,70 \\
\hline 15 & PT & 18.706 & 0,47 & 99,17 \\
\hline 16 & PSC & 15.075 & 0,38 & 99,54 \\
\hline 17 & PMN & 11.092 & 0,28 & 99,82 \\
\hline 18 & PMD & 7.124 & 0,18 & 100,00 \\
\hline & TOTAL & 3.996 .696 & 100 & - \\
\hline
\end{tabular}

FOnTE: Dados da Pesquisa (2019) 
De acordo com a Tabela 3, podemos observar que o partido político com o maior número de prefeituras sob seu comando é o Partido Socialista Brasileiro (PSB), em sequida vem o Partido da Social Democracia Brasileira (PSDB). Apesar de 18 partidos diferentes terem conquistado pelo menos uma prefeitura nas eleições de 2016, os seis primeiros partidos detem a fatia de $81,17 \%$ das cidades paraibanas.

Em relação a Tabela 4, é evidenciado a quantidade populacional sob o comando de cada partido político. Apesar de haver alteração em relação a Tabela 1, percebemos que os seis primeiros partidos são os mesmos, apenas trocaram alguma posição. Esses seis partidos políticos (PSB, PSDB, PMDB, PSD, PTB e DEM) comandam o orçamento de $85,30 \%$ da população paraibana.

Foi calculo o teste de Shapiro-Wilk com o intuito de verificarmos se a amostra dessa pesquisa poderia ser considerada "normal", com isso embasar a decisão de quais testes seriam mais adequado para comparar os anos de 2017 e 2018 no que tange as variáveis orçamento, credito adicional suplementar e especial e os valores que foram anulados. Na Tabela 5 estão descritos os resultados.

Tabela 5 - Teste de Shapiro-Wilk

\begin{tabular}{c|c|c}
\hline Variavel & Statistics Test & $p$-value \\
\hline Orçado & 0,20332 & $1,19 \mathrm{E}-39$ \\
\hline Suplementar & 0,36500 & $1,33 \mathrm{E}-36$ \\
\hline Especial & 0,29875 & $6,39 \mathrm{E}-38$ \\
\hline Anulado & 0,35523 & $8,35 \mathrm{E}-37$ \\
\hline Anulado/orçado & 0,93244 & $2,53 \mathrm{E}-13$ \\
\hline
\end{tabular}

FONTE: Dados da Pesquisa (2019)

Conforme pode ser visualizado na Tabela 5, a distribuição das variáveis não são normais, uma vez que a significância encontrada é menor do que 0.01 , indicando que os valores da statistics test pertencem à região crítica.

Na Tabela 6, é demonstrado os valores referentes aos créditos adicionais divididos em suplementar, especial e extraordinários nos dois anos da análise. Ademais, também pode ser visualizado os valores referentes ao que foi anulado. 
Tabela 6 - Créditos Adicionais (inserir mediana)

\begin{tabular}{|c|c|c|c|c|c|c|}
\hline & & Maior & Menor & $\begin{array}{l}\text { Desvio } \\
\text { Padrão }\end{array}$ & Média & $\begin{array}{l}\text { Wilcoxon } \\
\text { p-valor }\end{array}$ \\
\hline \multirow{2}{*}{ Orçado } & 2017 & 1.214 .683 .225 & 9.046 .933 & 90.922 .820 & 40.499 .689 & 6362 \\
\hline & 2018 & 1.406 .228 .932 & 9.619 .916 & 102.229 .269 & 42.434 .436 & $5,54 \mathrm{E}-10^{*}$ \\
\hline \multirow{2}{*}{ Suplementar } & 2017 & 121.816 .876 & 1.532 .400 & 14.121 .838 & 9.484 .731 & 16339 \\
\hline & 2018 & 218.114 .563 & 1.164 .477 & 17.371 .458 & 8.961 .277 & $3,54 \mathrm{E}-05^{*}$ \\
\hline \multirow{2}{*}{ Especial } & 2017 & 5.501 .030 & 0 & 640.106 & 256.462 & 6200,5 \\
\hline & 2018 & 14.006 .900 & 0 & 1.623 .619 & 492.863 & 0,424484 \\
\hline \multirow{2}{*}{ Extraordinário } & 2017 & 10.000 & 0 & 669 & 0 & \multirow{2}{*}{--} \\
\hline & 2018 & 0 & 0 & 0 & 0 & \\
\hline \multirow{2}{*}{ Anulado } & 2017 & 153.549 .514 & 1.532 .400 & 16.072 .318 & 9.985 .754 & 16384 \\
\hline & 2018 & 222.802 .049 & 957.736 & 18.160 .511 & 9.257 .605 & $2,89 \mathrm{E}-05^{*}$ \\
\hline
\end{tabular}

Nota: *Significante a um nível de $1 \%$

FONTE: Dados da Pesquisa (2019)

Em média o orçamento de cada prefeitura do Estado da Paraiba em 2017 correspondeu a pouco mais de $\mathrm{R} \$ 40 \mathrm{mi}$ lhões, em 2018 esse valor somou mais de $\mathrm{R} \$ 42$ milhões. O teste de wilcoxon revelou que esse aumento nos orçamentos das prefeituras de 2017 para 2018 foi estatisticamente significativo.

Podemos observar que existe um grande abismo entre os entes, os maiores orçamentos de 2017 e 2018 somam mais de $\mathrm{R} \$ 1.2$ Bilhões e $\mathrm{R} \$ 1.4$ Bilhões e o menor $\mathrm{R} \$ 9$ milhões, uma diferença de mais de 130 vezes.

Em relação aos créditos adicionais suplementares e especiais e ao que foi anulado, percebe-se que houve diminuição nos créditos adicionais suplementares e ao que foi anulado, o teste de wilcoxon revelou que essa diminuição de 2017 para 2018 foi estatisticamente significativa. Já com os créditos adicionais especiais houve aumento de 2017 para 2018, porém, sem significância estatística.

Apenas uma prefeitura fez uso do crédito extraordinário em 2017 e nenhuma em 2018.

Em relação aos totais anulados do orçamento, podemos afirmar que em média quase $\mathrm{R} \$ 10$ milhões foram anulados em 2017 e em 2018 teve uma diminuição para pouco mais de R\$9 milhões. Importante frisar que em média cada ente municipal tem um parlamento de pouco mais de $\mathrm{R} \$ 40$ milhões e em média quase $\mathrm{R} \$ 10$ milhões são anulados. Isso significa 
Revista de Gestão Pública

PRÁTICAS E DESAFIOS

ISSN: 2177-1243

dizer que em média quase $25 \%$ do que foi orçado foi anulado pelos entes.

Na Tabela 7, o total do que foi orçado na Lei Orcamentária Anual (LOA) foi dividido pelo que foi anulado. Nessa tabela é apresentado os resultados de todas as 223 prefeituras pertencentes a amostra do presente estudo.

Tabela 7 - Anulado/Orçado (\%)

\begin{tabular}{l|c|c|c}
\hline \multicolumn{1}{c|}{ Análise } & 2017 & 2018 & $\begin{array}{c}\text { Wilcoxon } \\
\text { p-valor }\end{array}$ \\
\cline { 1 - 2 } Média & 25,9 & 22,5 & \\
\cline { 1 - 2 } Mediana & 24,5 & 20,2 & \multirow{2}{*}{17181} \\
\cline { 1 - 2 } Moda & 26,4 & 36,8 & \multirow{2}{*}{$5,33 \mathrm{E}-07^{*}$} \\
\cline { 1 - 2 } Desvio Padrão & 10,9 & 10,2 & \\
\cline { 1 - 2 } Minimo & 7,5 & 4,4 & \\
\hline Máximo & 85,6 & 56,6 & \\
\hline
\end{tabular}

Nota: *Significante a um nível de 1

FONTE: Dados da Pesquisa (2019)

Em média 25,9\% em 2017 e 22,5\% em 2018 do que foi planejado foi anulado. O teste de wilcoxon demonstra que essa diminuição de anulação nos orçamentos das prefeituras de 2017 para 2018 foi estatisticamente significativa.

Uma das razões que podem explicar esse fenômeno é que 2017 foi o primeiro ano do mandato dos prefeitos. E que o ordenamento jurídico do Brasil, determina que durante o primeiro ano de mandato, os novos prefeitos irão cumprir o que foi estabelecido por seu antecessor.

Um dado que deve ser observado são os casos de valor máximo. Em 2017 teve uma prefeitura que anulou 85,6\% do que foi planejado no orçamento e em 2018 uma prefeitura anulou 56,6\%. Com intuito de esclarecer esses resultados, os dados dessas duas prefeituras estão descritos na Tabela 8. 
Tabela 8 - Maiores casos de Anulado/Orçado (\%)

\begin{tabular}{c|c|c|c|c|c}
\hline \multicolumn{7}{c}{ Prefeitura de Juazeirinho - Ano 2017 - PT do B - População 18.041 } \\
\hline Orçado & Suplementar & Especial & Extrardinário & Anulação & $\begin{array}{c}\text { Anulado/ } \\
\text { Orçado }\end{array}$ \\
\hline $24.385 .202,00$ & $19.539 .896,63$ & $540.000,00$ & 0,00 & $20.874 .651,06$ & $\mathbf{8 5 , 6 0 \%}$ \\
\hline \multicolumn{6}{c}{ Prefeitura de São José do Sabugi - Ano 2018 - DEM - População 4.134 } \\
\hline Orçado & Suplementar & Especial & Extrardinário & Anulação & $\begin{array}{c}\text { Anulado/ } \\
\text { Orçado }\end{array}$ \\
\hline $11.095 .149,00$ & $5.901 .011,00$ & $60.000,00$ & 0,00 & $6.287 .922,00$ & $\mathbf{5 6 , 6 7 \%}$ \\
\hline
\end{tabular}

FONTE: Dados da Pesquisa (2019)

A prefeitura da cidade de Juazeirinho, que tem população de pouco mais de 18 mil habitantes e que é comandada pelo partido político PT do B, orçou pouco mais de $\mathrm{R} \$ 24$ milhões, desse montante foi anulado quase $\mathrm{R} \$ 21$ milhões. Note-se que em 2018 aconteceu com a prefeitura da cidade de São José do Sabugi, que tem apenas 4.134 habitantes e é comandada pelo partido político DEM, teve orçamento de pouco mais de $\mathrm{R} \$ 11$ milhões e anulou pouco mais de R $\$ 6$ milhões.

\subsection{ANÁLISE INFERENCIAL COM TESTES DE MÉDIA POR PARTIDO POLÍTICO}

Em relação as anulações do orçamento, foram calculadas as médias e medianas de todos os partidos políticos em 2017 e em 2018, dos 18 partidos políticos pertencentes a amostra, 15 apresentaram médias inferiores em 2018 em relação a 2017. As 3 exceções foram os partidos PDT, PRP e PT. Esses partidos aumentaram as anulações do orçamento em 2018 em relação a 2017.

Após essa breve análise, foi calculado o teste não-paramétrico de Kruskal-Wallis com a finalidade de testar a hipotése proposta nessa pesquisa sob a luz da Teoria da Escolha Pública (TEP), os resultados desses testes estão descritos na Tabela 9. 
Tabela 9 - Análise por partido político

\begin{tabular}{|c|c|c|c|c|c|c|c|c|}
\hline Ano & \multicolumn{4}{|c|}{2017} & \multicolumn{4}{|c|}{2018} \\
\hline \multirow{2}{*}{$\begin{array}{l}\text { Partido } \\
\text { Político }\end{array}$} & \multicolumn{2}{|c|}{$\begin{array}{c}\text { Anulado/Orçado } \\
(\%)\end{array}$} & \multicolumn{2}{|c|}{ Teste Kruskal-Wallis } & \multicolumn{2}{|c|}{$\begin{array}{c}\text { Anulado/Orçado } \\
(\%)\end{array}$} & \multicolumn{2}{|c|}{ Teste Kruskal-Wallis } \\
\hline & Média & Mediana & $\begin{array}{c}\text { Test } \\
\text { Statistics }\end{array}$ & p-value & Média & Mediana & $\begin{array}{c}\text { Test } \\
\text { Statistics }\end{array}$ & p-value \\
\hline PSB & 26,94 & 25,08 & \multirow{18}{*}{16,9655} & \multirow{18}{*}{0,45670} & 22,61 & 21,88 & \multirow{18}{*}{8,6940} & \multirow{18}{*}{0,94937} \\
\hline PSDB & 24,52 & 24,46 & & & 22,76 & 21,17 & & \\
\hline PMDB & 25,46 & 24,52 & & & 22,19 & 19,92 & & \\
\hline PSD & 24,04 & 23,84 & & & 20,34 & 19,28 & & \\
\hline PTB & 23,72 & 22,05 & & & 20,90 & 16,05 & & \\
\hline DEM & 25,79 & 24,68 & & & 24,44 & 18,17 & & \\
\hline PR & 23,74 & 21,08 & & & 20,54 & 20,41 & & \\
\hline PDT & 23,62 & 21,90 & & & 26,01 & 23,13 & & \\
\hline $\mathrm{PP}$ & 30,40 & 28,19 & & & 25,96 & 22,11 & & \\
\hline PSC & 33,84 & 25,37 & & & 25,74 & 27,71 & & \\
\hline PT do B & 46,10 & 30,09 & & & 21,74 & 18,80 & & \\
\hline PSL & 27,55 & 23,70 & & & 22,69 & 24,46 & & \\
\hline PRB & 31,69 & 31,69 & & & 19,79 & 19,79 & & \\
\hline PTN & 38,46 & 38,46 & & & 19,66 & 19,66 & & \\
\hline PMD & 53,82 & 53,82 & & & 18,22 & 18,22 & & \\
\hline PMN & 32,04 & 32,04 & & & 24,35 & 24,35 & & \\
\hline PRP & 8,81 & 8,81 & & & 47,51 & 47,51 & & \\
\hline PT & 25,54 & 25,54 & & & 28,29 & 28,29 & & \\
\hline
\end{tabular}

FONTE: Dados da Pesquisa (2019)

De acordo com (Cruz, Corrar, \& Slomski, 2008) o principal item analisado na análise do teste de Kruskal-Wallis é o $p$-value, pois, se este valor for menor que o nível de significância utilizado, a hipótese nula não é aceita, se for maior, a mesma é aceita.

Conforme os resultados do teste de Kruskal-Wallis descritos na Tabela 8, nem em 2017 e nem em 2018 houveram diferença estatística significativa entre os partidos políticos em relação as anulações do orçamento. Logo, rejeita-se a $H_{1}$ proposta nessa pesquisa, em que o vinculo partidário dos prefeitos dos municípios paraibanos difere em relação a manipulação do orçamento no setor público.

Confirmando os achados desta pesquisa, estudo de (Rocha, 2009) concluiu que a abertura de créditos adicionais no Brasil apresenta características de orçamentos de países "pobres", dentre a principal característica um numero elevado de transferências entre categorias de gastos. 
Essa pesquisa corrobora com os pressupostos da Teoria das Escolhas Públicas, em que os agentes públicos tomam decisões levando em consideração interesses próprios ou de seu grupo e possuem comportamentos iguais no intuito de maximizarem a sua utilidade. Não fez diferença o vinculo partidário dos prefeitos dos municípios paraibanos com a manipulação do orçamento no setor público, através da anulação de créditos adicionais.

Essa baixa coerência ideológica foi encontrada no trabalho de (Zucco Jr, 2009) que afirma haver no sistema partidário brasileiro uma baixa coerência ideológica e que o fazer parte do governo (ou não) é o principal determinante do comportamento. (Scheeffer, 2018) também encontrou apoio nesses argumentos. Sua pesquisa demonstrou que o a ideologia partidária não prevalece quando estão em jogo recursos financeiros. Corroborando com esses achados, estudo de (Fabre, Engelage, Flach, \& Borgert, 2020) na área de saúde pública, indica que as escolhas dos gestores parecem se direcionar mais para o tratamento do que para a prevenção das doenças, o que contraria os preceitos do Sistema Único de Saúde (SUS), porém, essas escolhas dos governantes seguem prioridades individuais, conforme preconizado pela teoria da escolha pública.

\section{CONCLUSÃO}

Essa pesquisa teve como objetivo, a luz da teoria da escolha pública, relacionar o vínculo partidário dos prefeitos dos municípios paraibanos com a manipulação do orçamento no setor público, através da anulação de créditos adicionais. A análise dos resultados foi composta de duas partes, análise descritiva e análise de testes de diferenças de médias.

Os principais resultados da análise descritiva foram:

Apesar de 18 partidos diferentes terem conquistado pelo menos uma prefeitura nas eleições de 2016, os seis primeiros partidos (PSB, PSDB, PMDB, PSD, PTB e DEM) detem a fatia de 81,17\% das cidades paraibanas que representa $85,30 \%$ da população paraibana;

$>$ Em média o orçamento de cada prefeitura do Estado da Paraiba em 2017 correspondeu a pouco mais de R \$40 milhões, em 2018 esse valor somou mais de $\mathrm{R} \$ 42$ milhões;

Em relação aos créditos adicionais suplementares e especiais e ao que foi anulado, percebe-se que houve diminuição nos créditos adicionais suplementares e ao que foi anulado, em contrapartida, houve aumento de 2017 para 2018 com os créditos adicionais especiais; 
Em média, 25,9\% em 2017 e 22,5\% em 2018, do que foi planejado foi anulado.

Esses resultados se assemelham ao estudo de (Rocha, 2009) que afirma que no Brasil, o volume de créditos adicionais supera, e com excesso, os valores estipulados nas leis orçamentárias.

Em relação ao teste de diferença de média wilcoxon, que comparou os dados da amostra nos anos de 2017 e 2018, os principais achados foram:

Que o aumento nos orçamentos das prefeituras de 2017 para 2018 foi estatisticamente significativo;

> A diminuição de abertura de crédito adicional suplementar e a diminuição de anulação no orçamento de 2018 em relação a 2017 foi estatisticamente significativo;

> Que a diminuição da média do que foi anulado do orçamento de 2018 em relação a 2017 foi estatisticamente significativo.

Com o intuito de testar a teoria da escolha pública, a última análise foi em relação a hipótese dessa pesquisa, em que o vinculo partidário dos prefeitos dos municípios paraibanos difere em relação a manipulação do orçamento no setor público.

Conforme os resultados do teste de Kruskal-Wallis, nem em 2017 e nem em 2018, houveram diferenças estatísticas significativas entre os partidos políticos em relação as anulações do orçamento. Dessa forma, a hipótese proposta nessa pesquisa, foi rejeitada. Esse resultado encontra amparo nos pressupostos da teoria da escolha pública. 


\section{REFERÊNCIAS}

Almeida, H. M. De, \& Costa, A. V. (2019). Artigo

Orçamento Público como Mecanismo de Planejamento para a Gestão. Id on Line Rev. Mult. Psic., 13(1), 559-577.

Baldissera, J. F., Costa, R. F. da S., Asta, D. D., \& Fiirst, C. (2018). Influência do Ano Eleitoral, da Mudança de Gestor Público e do Mandato Eleitoral sobre a abertura de Créditos Adicionais. XVIII Inernational USP Conference in Accounting, 1-19.

BRASIL. (1964). Lei 4.320, de 17 de março de 1964. Institui normas de direito financeiro para elaboração e controle dos orçamentos e balanços da União, Estados, dos Municípios e do Distrito Federal. Brasília, DF: Diário Oficial da União.

Cruz, C. V. O. A., Corrar, L. J., \& Slomski, V. (2008). A Docência e o Desempenho dos Alunos dos Cursos de Graduação em Contabilidade no Brasil. Revista Contabilidade Vista e Revista, 19(4), 15-37.

Cruz, C. F. da, \& Afonso, L. E. (2018). Gestão fiscal e pilares da Lei de Responsabilidade Fiscal : evidências em grandes municípios. Revista de Administração Pública, 52(1), 126-148.

Dias, M. A. (2010). James Buchanan e a "Política" na escolha pública. Revista Estratégica, 9(08), 32-45. Retrieved from http:// estrategica.faap.br/ojs/index.php/estrategica/article/view/15

Fabre, V. V., Engelage, E., Flach, L., \& Borgert, A. (2020). Gastos com vigilância epidemiológica nos municípios de Santa Catarina. Revista Catarinense Da Ciência Contábil, 19(54), 2967. https://doi.org/10.16930/2237-766220202967

Fabre, V. V., Scheeffer, F., Dallabona, L. F., \& Kroetz, M. (2018). Análise dos gastos com gestão ambiental frente ao comportamento políticoideológico dos gestores, sob a ótica da teoria das escolhas políticas. Brazilian Journal of Development, 4(2), 514-531.

Grateron, I. R. G. (1999). Auditoria de Gestão : Utilização de Indicadores de Gestão no Setor Público Caderno de Estudos , São Paulo , FIPECAFI , n²1 - Maio a Agosto / 1999 Auditoria de Gestão : Utilização de Indicadores de Gestão no Setor Público Caderno de Estudos , São Paulo ,. Cadernos de Estudos, (21), 1-18.

Jr, C. Z. (2009). Ideology or What? Legislative Behavior in Multiparty Presidential Settings. The Journal of Politics, 71(3), 1076-1092. https://doi.org/10.1017/S0022381609090896 
Kanayama, R. L., Tomio, F. R. de L., \& Filho, I. N. R. (2017). Impeachment, créditos adicionais do governo federal e o processo decisório orçamentário: um novo dilema para o direito e para a política? Revista Da Faculdade de Direito - UFPR, 62(3), 323-347.

Martins, P., \& Correia, L. (2015). Determinantes dos Desvios Orçamentais nos Municípios Portugueses. Revista Portuguesa de Estudos Regionais, (39).

Pereira, P. T. (1997). A teoria da escolha pública (public choice): Uma abordagem neoliberal? Analise Social, 32(141), 419-442.

Procopiuck, M., Machado, E. T., Resende, D. A., \& Bessa, F. L. B. N. (2007). O Plano Plurianual Municipal no sistema de planejamento e orçamento brasileiro. Revista Do Serviço Público, 58(4), 397-415.

Rocha, C. M. C. (2009). Orçamento Público no Brasil: Um estudo dos créditos adicionais. Revista Contabilidade, Gestão e Governança, 4(2).

Sanches, O. M. (1996). A participação do poder legislativo na análise e aprovação do orçamento. Revista de Informação Legislativa, 33(131), 1-21. Retrieved from http://www2.camara. leg.br/atividade-legislativa/orcamentobrasil/orcamentouniao/ estudos/artigos/antes-de-2005/Artigo050.pdf\%0Ahttp:// www2.camara.leg.br/atividade-legislativa/orcamentobrasil/ orcamentouniao/estudos/artigos/antes-de-2005/Artigo030.pdf

Scheeffer, F. (2018). Ideologia e comportamento parlamentar na câmara dos deputados. Teoria E Pesquisa, 27(2), 167-188.

Udehn, L. (1995). The Limits of Public Choice: A Sociological Critique of the Economic Theory of Politics (1st Editio). London: Routledge. https://doi.org/https://doi.org/10.4324/9780203007907

Varela, P. S., \& Martins, G. D. E. A. (2009). Perfil dos gastos públicos versus perfil econômico-social dos municípios paulistas. $\mathrm{RCO}$ - Revista de Contabilidade e Organizações - FEARP/USP, 3(5), 80-97. 